\title{
Improving the functionality of surface-engineered yeast cells by altering the cell wall morphology of the host strain
}

\author{
Kentaro Inokuma ${ }^{1}$ - Yuki Kitada ${ }^{1} \cdot$ Takahiro Bamba $^{1} \cdot$ Yuma Kobayashi $^{1} \cdot$ Takahiro Yukawa $^{1} \cdot$ Riaan den Haan $^{2}$. \\ Willem Heber van $\mathrm{Zyl}^{3}$. Akihiko Kondo ${ }^{1,4,5} \cdot$ Tomohisa Hasunuma $^{1,4} \mathbb{C}$
}

Received: 22 April 2021 /Revised: 21 June 2021 / Accepted: 3 July 2021

(C) The Author(s), under exclusive licence to Springer-Verlag GmbH Germany, part of Springer Nature 2021

\begin{abstract}
The expression of functional proteins on the cell surface using glycosylphosphatidylinositol (GPI)-anchoring technology is a promising approach for constructing yeast cells with special functions. The functionality of surface-engineered yeast strains strongly depends on the amount of functional proteins displayed on their cell surface. On the other hand, since the yeast cell wall space is finite, heterologous protein carrying capacity of the cell wall is limited. Here, we report the effect of CCW12 and CCW14 knockout, which encode major nonenzymatic GPI-anchored cell wall proteins (GPI-CWPs) involved in the cell wall organization, on the heterologous protein carrying capacity of yeast cell wall. Aspergillus aculeatus $\beta$-glucosidase (BGL) was used as a reporter to evaluate the protein carrying capacity in Saccharomyces cerevisiae. No significant difference in the amount of cell wall-associated BGL and cell-surface BGL activity was observed between CCW12 and CCW14 knockout strains and their control strain. In contrast, in the CCW12 and CCW14 co-knockout strains, the amount of cell wall-associated BGL and its activity were approximately 1.4-fold higher than those of the control strain and CCW12 or CCW14 knockout strains. Electron microscopic observation revealed that the total cell wall thickness of the $C C W 12$ and $C C W 14$ co-knockout strains was increased compared to the parental strain, suggesting a potential increase in heterologous protein carrying capacity of the cell wall. These results indicate that the $C C W 12$ and $C C W 14$ co-knockout strains are a promising host for the construction of highly functional recombinant yeast strains using cell-surface display technology.
\end{abstract}

\section{Key points}

- CCW12 and/or CCW14 of a BGL-displaying S. cerevisiae strain were knocked out.

- CCW12 and CCW14 co-disruption improved the display efficiency of BGL.

- The thickness of the yeast cell wall was increased upon CCW12 and CCW14 knockout.

Keywords Saccharomyces cerevisiae · Yeast surface display $\cdot$ Glycosylphosphatidylinositol-anchored cell wall protein $\cdot$ cell wall morphology

Tomohisa Hasunuma

hasunuma@port.kobe-u.ac.jp

1 Graduate School of Science, Technology and Innovation, Kobe University, 1-1 Rokkodai-cho, Nada-ku, Kobe 657-8501, Japan

2 Department of Biotechnology, University of the Western Cape, Bellville 7530, South Africa

3 Department of Microbiology, Stellenbosch University, Private Bag X1, Matieland 7602, South Africa

4 Engineering Biology Research Center, Kobe University, 1-1 Rokkodai-cho, Nada-ku, Kobe 657-8501, Japan

5 Biomass Engineering Program, RIKEN, 1-7-22 Suehiro-cho, Tsurumi-ku, Yokohama, Kanagawa 230-0045, Japan

\section{Introduction}

The expression of functional proteins on the cell surface is a promising approach to add special functions to microbial cells and yeast Saccharomyces cerevisiae is the most frequently used host microorganism for this approach. Yeast cell-surface display technology essentially relies on the expression of a target protein in the cell wall through linkage with a genetically fused anchoring protein, typically a glycosylphosphatidylinositol (GPI)-anchored cell wall protein (GPI-CWP). Cell-surfaceengineered yeast strains constructed using this technology 
can be used for a wide range of applications, such as the engineering and screening of enzymes, antibodies, or peptides (Angelini et al. 2015; Grzeschik et al. 2017; Li et al. 2007), biocontrol agents (Zhao et al. 2020), and the production of whole cell catalysts for bioconversion (Liu et al. 2016; Inokuma et al. 2018), biodegradation (Shibasaki et al. 2009), and biosensing (Shibasaki et al. 2001; Wang et al. 2013). Furthermore, the applications of antigen-displaying cells as vaccines against influenza viruses were recently reported (Lei et al. 2016; Lei et al. 2020).

The functionality of yeast cells strongly depends on the amount of proteins displayed on their cell surface and many studies to efficiently immobilize heterologous proteins to cell surface have been reported over the years. A typical method is the overexpression of target genes using constitutive promoters with high strength and/or adding extra copies of gene cassettes (Yamakawa et al. 2012; Inokuma et al. 2015). Optimization of the gene cassette introduced into yeast is another promising method for improving the efficiency of yeast surface display. We have successfully enhanced the cellsurface $\beta$-glucosidase (BGL) and endoglucanase (EG) activity by 17 - and 108 -fold, respectively, by optimizing the gene cassette components (combination of promoter, GPI anchoring region, and secretion signal sequences) (Inokuma et al. 2014; Inokuma et al. 2016).

Another approach to improve the display efficiency of heterologous proteins is the genetic engineering of the host yeast strain. Since the extracellular transport mechanism of GPI-attached proteins is fundamentally the same as that of secretory proteins and surface display data correlate well with secretion data (Shusta et al. 1999), the yeast cell-surface display technology can be used to explore targets to improve protein secretion efficiency. Hence, many of the reported engineering targets for improving surface display efficiency are involved in the protein secretion pathway. In addition, there are some reports on improving the surface display efficiency via engineering genes encoding yeast cell wall proteins. Wentz and Shusta (2007) performed a genome-wide screening of engineering targets that improve the display of heterologous proteins and found that overexpression of some genes encoding nonenzymatic GPI-CWPs (Ccw12p, Cwp2p, and Sed1p) promotes the display of a single-chain T-cell receptor. Bamba et al. (2018) reported approximately $20 \%$ increase in the amount of the cell wall-associated BGL by disruption of the SED1 gene. These reports suggested that nonenzymatic GPI-CWPs are promising targets to improve surface display efficiency. However, there is limited knowledge about the engineering effect of cell wall proteins, especially on the heterologous protein carrying capacity of the yeast cell wall.
In the present study, we focused on $\mathrm{Ccw} 12 \mathrm{p}$ and Ccw $14 p$, major nonenzymatic GPI-CWPs involved in cell wall organization in $S$. cerevisiae (https://www. yeastgenome.org/go/GO:0031505), and investigated the effect of disrupting the CCW12 and CCW14 on the heterologous protein carrying capacity of the cell wall using Aspergillus aculeatus BGL1 as the reporter protein. Ccw $12 p$ is a heavily glycosylated GPI-CWP of 133 amino acids concentrated at sites of active cell wall synthesis such as the future bud site, the septum, and the lateral walls of enlarging daughter cells, and has a major role in the cell wall integrity in S. cerevisiae (Ragni et al. 2007; Ragni et al. 2011). Ccw14p is a GPI-CWP of 238 amino acids localized to the inner cell wall (Moukadiri et al. 1997), and involved in cell wall stability (Lesage and Bussey 2006) and biofilm formation (Moreno-García et al. 2018). Ccw12p and Ccw14p have been reported to be related to yeast cell wall chitin (Klis 1994; Moukadiri et al. 1997), which plays an important role in the mechanical strength of the cell wall (Arroyo et al. 2016). First, $C C W 12$ and $C C W 14$ of a BGLdisplaying $S$. cerevisiae strain were knocked out individually or simultaneously using a CRISPR/Cas9-mediated gene knockout method. Then, cell-surface BGL activity and the amount of cell wall-associated BGL in the constructed strains were compared to those of the parental strain. Finally, the effect of the CCW12 and CCW14f knockout on the cell wall morphology of the BGLdisplaying strains was investigated using transmission electron microscopy.

\section{Materials and methods}

\section{Strains and media}

Escherichia coli strain DH5 $\alpha$ (Toyobo, Osaka, Japan) was used for the construction and propagation of all plasmids as described previously (Inokuma et al. 2016). All yeast strains used in this study were derived from the haploid strain S. cerevisiae BY4741 (Life Technologies, Carlsbad, CA, USA). Genetic properties of the S. cerevisiae strains used in this study are summarized in Table 1.

$S$. cerevisiae transformants were screened and cultivated as previously described (Inokuma et al. 2016). The culture broth was sampled every $24 \mathrm{~h}$, and yeast cells were harvested via centrifugation at $1000 \times g$ for $5 \mathrm{~min}$, washed twice with distilled water, and centrifuged again at $1000 \times g$ for $5 \mathrm{~min}$. The wet cell weight of the washed yeast cells was determined by weighing the cell pellet and the dry cell weight of a yeast cell was determined (approximately $0.15 \times$ its wet cell weight (Inokuma et al. 2014)). Cell pellets were used for enzyme assays and ethanol fermentation. 
Table 1 Characteristics of yeast strains and plasmids used in this study

\begin{tabular}{|c|c|c|}
\hline Yeast strains and plasmids & Relevant genotype & Source \\
\hline \multicolumn{3}{|l|}{ S. cerevisiae } \\
\hline BY4741 & MATa his $3 \Delta 1$ leu $2 \Delta 0$ met $15 \Delta 0$ ura $3 \Delta 0$ & Life Technologies \\
\hline BY-BG-SSS & $\begin{array}{l}\text { BY4741/pIBG-SSS }\left[S E D 1_{\mathrm{P}}-S E D 1_{\mathrm{SP}}-A \text {. aculeatus }\right. \\
\left.\quad B G L 1-S E D 1_{\mathrm{A}}-S A G 1_{\mathrm{T}}, \text { leu } 2 \Delta 0 \text { met1 } 150 \text { ura } 30\right]\end{array}$ & Inokuma et al. (2016) \\
\hline BY-BG-SSSD & $\begin{array}{l}\mathrm{BY} 4741 / \mathrm{pIBG}-\mathrm{SSSD}\left[S E D 1_{\mathrm{P}}-S E D 1_{\mathrm{SP}}-A . \text { aculeatus }\right. \\
\left.\quad B G L 1-S E D 1_{\mathrm{A}}-D I T 1_{\mathrm{T}}, \text { leu } 2 \Delta 0 \text { met15 } \Delta 0 \text { ura } 300\right]\end{array}$ & This study \\
\hline ccw12-BGSD & $\begin{array}{l}\text { BY-BG-SSSD } C C W 12 \Delta\left[S E D 1_{\mathrm{P}}-S E D 1_{\mathrm{SP}}\right. \\
\quad \text { A. aculeatus } B G L 1-S E D 1_{\mathrm{A}}-D I T 1_{\mathrm{T}} \text {, leu } 2 \Delta 0 \\
\quad \text { met1 } 50 \text { ura } 30 \text { ccw } 12 \Delta]\end{array}$ & This study \\
\hline ccw14-BGSD & $\begin{array}{l}\text { BY-BG-SSSD } C C W 14 \Delta\left[S E D 1_{\mathrm{P}}-S E D 1_{\mathrm{SP}}-\right. \\
\quad \text { A. aculeatus } B G L 1-S E D 1_{\mathrm{A}}-D I T 1_{\mathrm{T}}, \text { leu } 2 \Delta 0 \\
\quad \text { met15 } \Delta 0 \text { ura } 30 \text { ccw } 14 \Delta]\end{array}$ & This study \\
\hline ccw12/ccw14-BGSD & $\begin{array}{l}\text { BY-BG-SSSD CCW12 } \triangle C C W 14 \Delta \\
{\left[S E D 1_{\mathrm{P}}-S E D 1_{\mathrm{SP}}-A . \text { aculeatus }\right.} \\
\quad B G L 1-S E D 1_{\mathrm{A}}-D I T 1_{\mathrm{T}}, \text { leu } 2 \Delta 0 \text { met } 15 \Delta 0 \text { ura } 3 \Delta 0 \\
\text { ccw12 } \Delta \text { ccw } 14 \Delta]\end{array}$ & This study \\
\hline BY-EG-SSSD & $\begin{array}{l}\text { BY4741/pIEG-SSSD }\left[S E D 1_{\mathrm{P}}-S E D 1_{\mathrm{SP}}-\text { T. reesei }\right. \\
\left.\quad E G I I-S E D 1_{\mathrm{A}}-D I T 1_{\mathrm{T}}, \text { leu } 2 \Delta 0 \text { met15 } 150 \text { ura } 300\right]\end{array}$ & This study \\
\hline ccw12/ccw14-EGSD & $\begin{array}{l}\text { BY-EG-SSSD } C C W 12 \Delta C C W 14 \Delta\left[S E D 1_{\mathrm{P}}-S E D 1_{\mathrm{SP}}\right. \\
\quad \text { T. reesei } E G I I-S E D 1_{\mathrm{A}}-D I T 1_{\mathrm{T}} \text {, leu } 2 \Delta 0 \text { met } 15 \Delta 0 \\
\quad \text { ura3 } \Delta 0 \text { ccw12 } \Delta \text { ccw } 14 \Delta]\end{array}$ & This study \\
\hline BY-BG-SSAD & $\begin{array}{l}\text { BY4741/pIBG-SSAD }\left[S E D 1_{\mathrm{P}}-S E D 1_{\mathrm{SP}}-A \text {. aculeatus }\right. \\
\left.\quad B G L 1-S A G 1_{\mathrm{A}}-D I T 1_{\mathrm{T}}, \text { leu } 2 \Delta 0 \text { met } 15 \Delta 0 \text { ura } \Delta 0\right]\end{array}$ & This study \\
\hline ccw12/ccw14-BGAD & $\begin{array}{l}\mathrm{BY} 4741 / \mathrm{pIBG}-\mathrm{SSAD} C C W 12 \Delta C C W 14 \Delta \\
{\left[S E D 1_{\mathrm{P}}-S E D 1_{\mathrm{SP}}-A . \text { aculeatus } B G L 1-S A G 1_{\mathrm{A}}\right.} \\
-D I T 1_{\mathrm{T}}, \text { leu } 2 \Delta 0 \text { met } 15 \Delta 0 \text { ura } 30 \text { ccw } 12 \Delta \\
\text { ccw14 } \Delta]\end{array}$ & This study \\
\hline \multicolumn{3}{|l|}{ Plasmids } \\
\hline pIBG-SSS & $\begin{array}{l}\text { HIS3 SED } 1_{\mathrm{P}}-S E D 1_{\mathrm{SP}}-A . \text { aculeatus } \\
\quad B G L 1-S E D 1_{\mathrm{A}}-S A G 1_{\mathrm{T}}\end{array}$ & Inokuma et al. (2016) \\
\hline pIBG-SSSD & $\begin{array}{l}H I S 3 S E D 1_{\mathrm{P}}-S E D 1_{\mathrm{SP}}-A . \text { aculeatus } \\
\quad B G L 1-S E D 1_{\mathrm{A}}-D I T 1_{\mathrm{T}}\end{array}$ & This study \\
\hline pIEG-SSS & $H I S 3 S E D 1_{\mathrm{P}}-S E D 1_{\mathrm{SP}}-T$. reesei $E G I I-S E D 1_{\mathrm{A}}-S A G 1_{\mathrm{T}}$ & Inokuma et al. (2016) \\
\hline pIEG-SSSD & $H I S 3 S E D 1_{\mathrm{P}}-S E D 1_{\mathrm{SP}}-$ T. reesei $E G I I-S E D 1_{\mathrm{A}}-D I T 1_{\mathrm{T}}$ & This study \\
\hline pIBG13 & HIS3 TDH $3_{\mathrm{P}}-A$. aculeatus $B G L 1-S A G 1_{\mathrm{A}}-S A G 1_{\mathrm{T}}$ & Katahira et al. (2006) \\
\hline pIBG-SSAD & $\begin{array}{l}\text { HIS3 SED1 } 1_{\mathrm{P}}-S E D 1_{\mathrm{SP}}-A . \text { aculeatus } \\
\quad B G L 1-S A G 1_{\mathrm{A}}-D I T 1_{\mathrm{T}}\end{array}$ & This study \\
\hline pGK415 & CEN-ARS $L E U 2 P G K 1_{\mathrm{P}}-P G K 1_{\mathrm{T}}$ & Ishii et al. (2009) \\
\hline Cas9_Base & $\begin{array}{l}\text { K. marxianus ARS7, K. marxianus CEN D, kanMX } \\
\quad P D C 1_{\mathrm{P}}-\text { Cas } 9-T D H 3_{\mathrm{T}}\end{array}$ & $\begin{array}{l}\text { Nambu-Nishida et al. } \\
\quad(2017)\end{array}$ \\
\hline pCL-Cas9 & $\begin{array}{l}\text { CEN-ARS LEU2 } \\
\quad T E F 1_{\mathrm{P}}-\mathrm{SV} 40_{\mathrm{NLS}}-\text { Cas } 9-\mathrm{SV} 40_{\mathrm{NLS}}-C Y C 1_{\mathrm{T}}\end{array}$ & This study \\
\hline pGK426 & $2 \mu$ ori $U R A 3 P G K 1_{\mathrm{P}}-P G K 1_{\mathrm{T}}$ & Ishii et al. (2009) \\
\hline pSUP4t & $2 \mu$ ori $U R A 3 S U P 4_{\mathrm{T}}$ & This study \\
\hline p2gRNA-CCW12 & $2 \mu$ ori $U R A 3 S N R 52_{\mathrm{P}}-\mathrm{gRNA}$ for $C C W 12-S U P 4_{\mathrm{T}}$ & This study \\
\hline p2gRNA- CCW14 & $2 \mu$ ori $U R A 3 S N R 52_{\mathrm{P}}-\mathrm{gRNA}$ for $C C W 14-S U P 4_{\mathrm{T}}$ & This study \\
\hline p2gRNA-CCW12/CCW14 & $\begin{array}{l}2 \mu \text { ori } U R A 3 S N R 52_{\mathrm{P}}-\mathrm{gRNA} \text { for } C C W 12-S U P 4_{\mathrm{T}} \\
\quad S N R 52_{\mathrm{P}}-\mathrm{gRNA} \text { for } C C W 14-S U P 4_{\mathrm{T}}\end{array}$ & This study \\
\hline
\end{tabular}

A. aculeatus, Aspergillus aculeatus; T. reesei, Trichoderma reesei; K. marxianus, Kluyveromyces marxianus; $P$ promoter, $S P$ secretion signal peptide sequence, $A$ anchoring region, $T$ terminator, $N L S$ nuclear localization signal

\section{Plasmid construction and yeast transformation}

The plasmids and primers used in this study are listed in Table 1 and Supplemental Table S1, respectively. Details on the construction of plasmids and yeast transformation are provided as Supplemental Text S1. All plasmids used in this study were transformed into $S$. cerevisiae using the lithium acetate method (Chen et al. 1992). 


\section{CRISPR/Cas9-mediated gene knockout with a double- stranded oligonucleotide}

$C C W 12$ and/or $C C W 14$ knockout strains were constructed using the CRISPR/Cas9-mediated gene knockout method (Jakočiūnas et al. 2015). The double-stranded oligo-nucleotides (dsOrigos) used in this study are listed in Supplemental Table S2. Specific guide RNAs (gRNAs) targeting CCW12 and CCW14 were designed using CHOPCHOP v3 (http:// chopchop.cbu.uib.no). gRNAs without $100 \%$ identity to other loci in the chromosomal DNA of the $S$. cerevisiae S288c strain were selected.

Briefly, the pCL-Cas9 plasmid was transformed into BY-BGSSSD, BY-EG-SSSD, and BY-BG-SSAD to express Cas9. Next, appropriate gRNA expression plasmids were transformed into the Cas9-expressing strain with $1 \mathrm{nmol}$ of corresponding dsOrigos, and the transformants were cultivated on selective agar plates for $72 \mathrm{~h}$ to knock out $C C W 12$ and/or CCW14. Base editing of the targeted loci was validated via Sanger sequencing. Finally, the $C C W 12$ and/or $C C W 14$ knockout strains were cultivated in the yeast extract peptone dextrose (YPD) medium for $24 \mathrm{~h}$ to eliminate Cas9 and gRNA expression plasmids. The plasmid elimination was verified by screening on agar plates with selective pressure for each plasmid. The strains in which both plasmids were eliminated were used for subsequent experiments as $C C W 12$ and/or CCW14 knockout strains.

\section{Enzyme assays}

BGL and EG activities of washed yeast cell pellets were evaluated as described previously (Inokuma et al. 2016). Briefly, BGL activity was assayed at $\mathrm{pH} 5.0$ and $30^{\circ} \mathrm{C}$ with $2 \mathrm{mM} p$ nitrophenyl- $\beta$-D-glucopyranoside ( $p$ NPG) as substrate. One unit of BGL activity was defined as the amount of enzyme required to liberate $1 \mu \mathrm{mol}$ of $p$-nitrophenol per min. EG activity for water-insoluble cellulose was assayed at $\mathrm{pH} 5.0$ and $38^{\circ} \mathrm{C}$ using water-insoluble AZCL-HE-Cellulose (Cellazyme $\mathrm{C}$ tablets; Megazyme, Bray, Ireland) as the substrate.

Transcript quantification of $B G L 1$ using real-time PCR

The transcript levels of $B G L 1$ were quantified using realtime PCR as described previously (Liu et al. 2017). The primers used are listed in Supplemental Table S1. Gene expression levels of target genes were normalized to those of the housekeeping $\beta$-tubulin gene (TUB2).

\section{Relative quantitative analysis of cell wall-associated BGL}

The identification and relative quantification of BGL in the yeast cell wall were performed based on precise mass measurements of tryptic peptides from the reporter protein using nanoscale ultra-pressure liquid chromatography-electrospray ionization quadrupole time-of-flight tandem mass spectrometry (nano-UPLC-MS ${ }^{\mathrm{E}}$ ) and ProteinLynx Global SERVER v3.0 (Waters Corporation, Milford, MA, USA), as described previously (Bamba et al. 2018). A minor modification was the use of an AQC M-Class HSS T3 Column (75 $\mu \mathrm{m}$ $\times 150 \mathrm{~mm}$; particle size, $1.8 \mu \mathrm{m}$; Waters Corporation) as the analytical column.

\section{Electron microscopy analysis}

Rapid freezing and freeze-substitution of washed cell pellets were carried out as described previously (Inokuma et al. 2020). The substituted samples were transferred to $-20{ }^{\circ} \mathrm{C}$ for $3 \mathrm{~h}$ and then warmed to $4{ }^{\circ} \mathrm{C}$ over $4 \mathrm{~h}$. Next, they were dehydrated in ethanol 3 times at room temperature for $30 \mathrm{~min}$ each and continuously dehydrated with ethanol overnight. Infiltration was performed with propylene oxide (PO) and resin (Quetol-651; Nisshin EM Co., Tokyo Japan) at room temperature $[100 \%$ PO for $30 \mathrm{~min} ; 100 \%$ PO for $30 \mathrm{~min}$; PO:resin 50:50 for $3 \mathrm{~h} ; 100 \%$ resin overnight]. The resins were then polymerized at $60^{\circ} \mathrm{C}$ for $48 \mathrm{~h}$ and cut into ultrathin sections of $70 \mathrm{~nm}$ thick using an ultramicrotome (Ultracut CUT; Leica, Vienna, Austria). The ultrathin sections were placed on copper grids, stained with $2 \%$ uranyl acetate for $15 \mathrm{~min}$ and lead stain solution (Sigma-Aldrich, St. Louis, MO, USA) for $3 \mathrm{~min}$ at room temperature. They were observed using a transmission electron microscope (JEM1400Plus; JOEL Ltd., Tokyo Japan) at an acceleration voltage of $100 \mathrm{kV}$. Digital images $(3296 \times 2472$ pixels) were taken with a CCD camera (EM-14830RUBY2; JOEL Ltd.).

\section{Sensitivity of yeast cells to chitin-binding reagents}

Yeast cells were grown in the YPD medium to exponential phase. Cells were harvested and resuspended in sterile water at an $\mathrm{OD}_{600}$ of 1 (Approximately $10^{8}$ cells $/ \mathrm{mL}$ ). Serial 10 -fold dilutions thereof were prepared and spotted $(5 \mu \mathrm{L})$ onto $\mathrm{YPD}$ plates alone or containing $20 \mu \mathrm{g} / \mathrm{mL}$ Calcofluor white (CFW) or $30 \mu \mathrm{g} / \mathrm{mL}$ Congo red (CR). Growth on plates was evaluated after 2 days of incubation at $30^{\circ} \mathrm{C}$.

\section{Statistical analysis}

Student's $t$-tests with Bonferroni correction were used to compare groups of values. Difference with confidence level of $95 \%(p<0.05)$ was considered statistically significant.

\section{Results}

\section{Construction of BGL-displaying S. cerevisiae strains}

To evaluate the effect of $C C W 12$ and $C C W 14$ disruptions on the surface display efficiency of heterologous proteins, we 
used A. aculeatus BGL1 as the reporter protein as it has been reported that this enzyme shows a good proportional relationship between its activity and abundance in the cell wall (Bamba et al. 2018; Inokuma et al. 2020). S. cerevisiae Sedlp, which is a stress-induced nonenzymatic GPI-CWP, was used as the anchoring domain for the cell-surface display because this protein has an excellent effect on the display of heterologous proteins including BGL1 (Inokuma et al. 2014; Inokuma et al. 2016). BGL1 was genetically fused Sed1p and the gene cassette for the expression of this fusion protein was integrated into the HIS3 locus of the chromosomal DNA of $S$. cerevisiae BY4741 via homologous recombination. We adopted the terminator sequence derived from $S$. cerevisiae DIT1 (Ito et al. 2016) to the BGL-displaying cassette because the DIT1 terminator exhibited high performance in the surface display of BGL1 compared with the conventional SAG1 terminator (Supplemental Fig. S1). CCW12 and CCW14 of the constructed BGL-displaying strains (BY-BG-SSSD) were then knocked out individually or simultaneously using the CRISPR/Cas9-mediated gene knockout method (Jakočiūnas et al. 2015) as described in the Materials and methods. Data obtained via Sanger sequencing of targeted loci from 4 colonies of each transformation showed stop codons in all the genomic contexts according to dsOligo template designs (Fig. 1). The constructed strains, ccw12-BGSD (CCW12 $\Delta$ ), ccw14-BGSD (CCW14 $\Delta$ ), and ccw12/ccw14-BGSD $(C C W 12 \Delta C C W 14 \Delta)$, were used in subsequent experiments with BY-BG-SSSD as the reference strain. The detailed information of these strains is shown in Table 1.

\section{Enzyme activity and relative quantity of cell wall- associated BGL1}

The BGL-displaying strains were cultivated at $30{ }^{\circ} \mathrm{C}$ for $96 \mathrm{~h}$ and cell-surface BGL activity was evaluated every $24 \mathrm{~h}$. BGL activity of these strains reached a plateau after $48 \mathrm{~h}$ of cultivation (Fig. 2a). No significant difference in the cell-surface BGL activity was observed between the control strain (BYBG-SSSD) and $C C W 12$ or $C C W 14$ knockout strains (ccw12-
BGSD and ccw14-BGSD). In contrast, in the $C C W 12$ and CCW14 co-knockout strains (ccw12/ccw14-BGSD), the cellsurface BGL activity was significantly higher than that of the control strain (BY-BG-SSSD) and the control strain (BY-BG$\mathrm{SSSD}$ ) and $C C W 12$ or $C C W 14$ knockout strains (ccw12BGSD and ccw14-BGSD). The BGL activity of the ccw12/ ccw14-BGSD strain reached $1250 \pm 11 \mathrm{U} / \mathrm{g}$ dry cells after 48 $\mathrm{h}$, which was approximately 1.4 -fold higher than that of the control strain ( $826 \pm 23 \mathrm{U} / \mathrm{g}$ dry cells). During cultivation, no significant growth defects were observed due to $C C W 12$ and CCW14 knockout (Fig. 2b).

We also investigated the expression levels of $A$. aculeatus $B G L 1$ in these strains using real-time PCR. No significant difference was observed in the expression levels of the gene in these strains after $48 \mathrm{~h}$ of cultivation (Fig. 2c).

Subsequently, the relative quantification of cell wallassociated BGL in these strains was performed using nanoUPLC-MS ${ }^{\mathrm{E}}$. The amount of cell wall-associated BGL per unit dry cell weight of ccw12/ccw14-BGSD was approximately 1.4-fold higher than that of the control strain, while that of ccw12-BGSD and ccw14-BGSD did not show any significant change (Fig. 2d). This result correlated well with cell-surface BGL activity of these strains (Fig. 2a), suggesting that the increased cell-surface BGL activity in ccw12/ccw14-BGSD was due to the increase in the amount of cell wall-associated BGL.

\section{Electron microscopic observation of BGL-displaying cells}

In order to understand the effect of $C C W 12$ and $C C W 14$ disruption better, cell wall morphology of the BGL-displaying yeast strains was observed under a transmission electron microscope (Fig. 3). Compared to the control strain (BY-BGSSSD, Fig. 3a), the cell wall of the ccw12-BGSD strain appeared noticeably darker, indicating an increased electron density (Fig. 3b). Although there was no significant change in total cell wall thickness, the proportion of the outer mannan layer was significantly increased. In contrast, in the ccw14-

\section{CCW12} (PAM/STOP)

BY4741: ATAATGCAATTTTCTACTGTCGCTTCTATCGCCGCTGTCGCCGCTGTCGCTTCTGCCGCTGCTAACGTTACCACTGCTACTGTCAGCCAAGAATCTACCA dsOligo: ATAATGCAATTTTCTACTGTCGCTTCTATCTAAGCTGTCGCCGCTGTCGCTTCTGCCGCTGCTAACGTTACCACTGCTACTGTCAGCCAAGAATCTACCA Mutant: ATAATGCAATTTTCTACTGTCGCTTCTATCTAAGCTGTCGCCGCTGTCGCTTCTGCCGCTGCTAACGTTACCACTGCTACTGTCAGCCAAGAATCTACCA

\section{CCW14}

(PAM/STOP)

BY4741: TCTTTGGCATTGTTGTCGAAGGAAGTCTTAGCAACACCTCCAGCTTGTTTATTGGCCTGTGTTGCGCAAGTCGGCAAATCCTCTTCCACATGTGACTCTT dsOligo: TCTTTGGCATTGTTGTCGAAGGAAGTCTTAGCAACATAACCAGCTTGTTTATTGGCCTGTGTTGCGCAAGTCGGCAAATCCTCTTCCACATGTGACTCTT

Mutant: TCTTTGGCATTGTTGTCGAAGGAAGTCTTAGCAACATAACCAGCTTGTTTATTGGCCTGTGTTGCGCAAGTCGGCAAATCCTCTTCCACATGTGACTCTT

Fig. 1 Sequence alignments of CCW12 and CCW14 compared to their respective dsOligos. The sense strands of the target sites are shown. The green sequences of the wild-type reference sequence denote the protospacer adjacent motif (PAM) sites. The red sequences indicate stop codons replacing the PAM sites. Sequences present in the gRNAs are underlined 

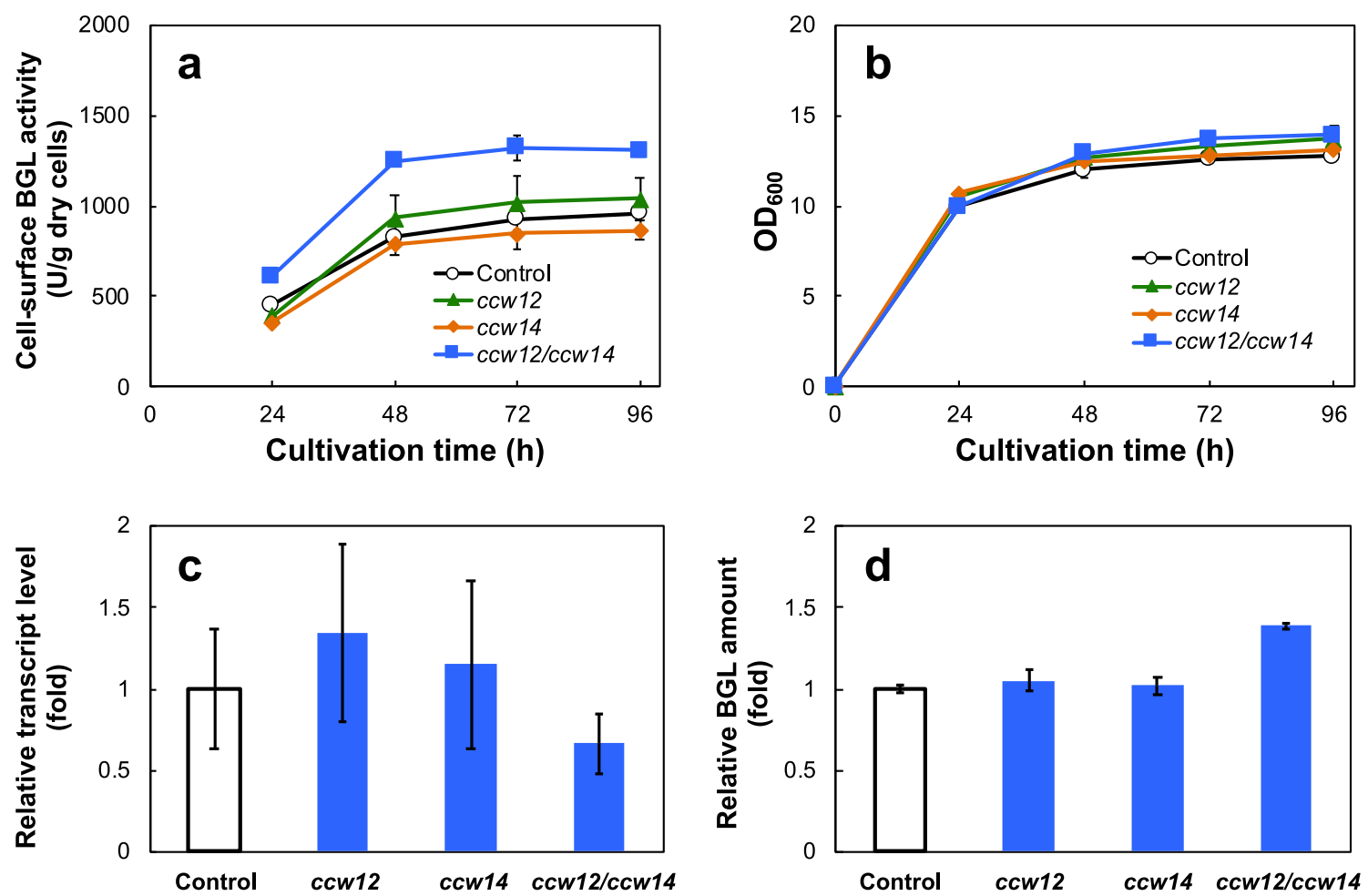

Fig. 2 Effects of $C C W 12$ and/or CCW14 knockout on BGL-displaying yeast. a Time-course of cell-surface BGL activities. b Cell growth of BGL-displaying yeasts. c Comparison of transcript levels of BGL1encoding genes after cultivation in YPD medium for $48 \mathrm{~h}$. The relative transcript level of each gene is shown as a fold-change in mRNA levels

relative to the average level detected in the control strain (BY-BG-SSSD). d Relative quantification of BGL1 in the cell walls by nano-UPLC-MS ${ }^{\mathrm{E}}$. The amount of BGL1 was normalized to the dry cell weight of each strain. Data are presented as the means \pm standard deviation $(n=3)$

BGSD strain, the inner glucan layer was less dense and brushlike fibers in the outer mannan layer were reduced and disturbed (Fig. 3c). In the ccw12/ccw14-BGSD strain, the density of the cell wall was intermediate between ccw12-BGSD and ccw14-BGSD, while the total cell wall thickness was noticeably increased (Fig. 3d; 200-230 nm) compared to the other three strains (Fig. 3a, b, and c; 140-170 nm).

\section{Discussion}

The $C C W 12$ and $C C W 14$ genes encode major nonenzymatic GPI-CWPs involved in cell wall organization in S. cerevisiae (https://www.yeastgenome.org/go/GO:0031505). In this study, we investigated the effect of $C C W 12$ and $C C W 14$ knockout on the surface display efficiency of heterologous proteins in yeast. No significant difference in the amount of cell wall-associated BGL per cell weight was observed between strains in which $C C W 12$ or $C C W 14$ was knocked out and their control strain. In contrast, in the $C C W 12$ and $C C W 14$ co-knockout strains, the amount of cell wall-associated BGL was approximately 1.4-fold higher than that of the control strain and $C C W 12$ or $C C W 14$ knockout strains (Fig. 2d). With the increase of the cell wall-associated BGL, the $C C W 12$ and $C C W 14$ co-knockout strains showed improved

cell-surface BGL activity (Fig. 2a) compared to the control strain and $C C W 12$ or $C C W 14$ knockout strains, while no significant growth defects were observed due to the knockout of these genes (Fig. 2b).

We also conducted electron microscopy analysis of the ultrathin sections of BGL-displaying strains and revealed their morphological differences (Fig. 3). ccw12-BGSD and ccw14BGSD strains showed contrasting morphological abnormalities in the cell wall; i.e., the cell wall density was higher in the ccw12-BGSD strain and lower in the ccw14-BGSD strain than that in their parental strain (BY-BG-SSSD). In contrast, $C C W 12$ and $C C W 14$ co-disruption had an unexpected morphological phenotype. The total cell wall thickness of the ccw12/ccw14-BGSD strain was significantly increased (Fig. 3d; 200-230 nm) compared to the other three strains (Fig. 3a, $\mathrm{b}$, and c; 140-170 nm). In the GPI anchoring technology, GPIattached heterologous proteins are immobilized in the yeast cell wall through covalent linkage to a $\beta-(1$ to 6$)$ glucan ( $\mathrm{Lu}$ et al. 1994). We previously reported that GPI-attached heterologous proteins in the cell wall are sterically immobilized in the cell wall space (Inokuma et al. 2020). The observations shown in Fig. 3 suggest that the increased BGL amount in the ccw12/ccw14-BGSD strain was due to an increase in the protein capacity of the cell wall with the expansion of the cell wall space. 
Fig. 3 Electron micrographs of ultrathin sections of a BY-BGSSSD, b ccw12-BGSD, $\mathbf{c}$ ccw14BGSD, and $\mathbf{d}$ ccw12/14-BGSD cells
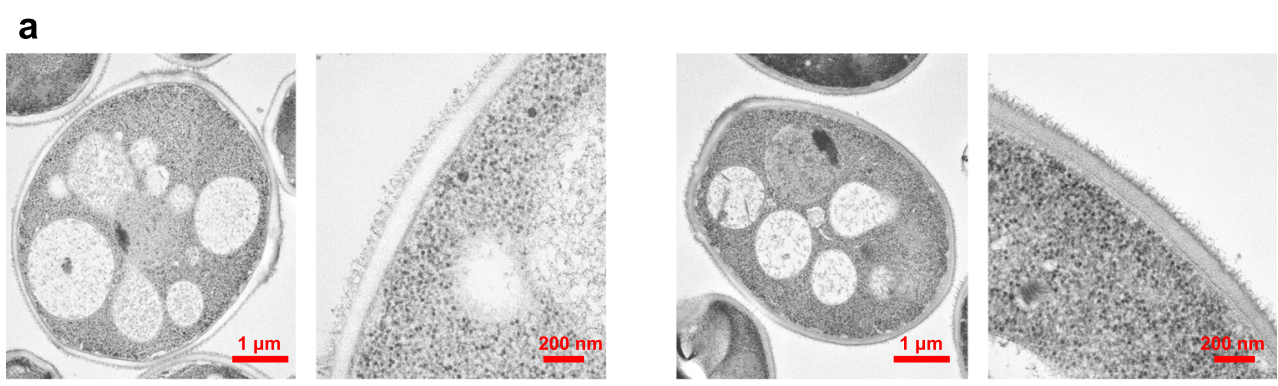

b
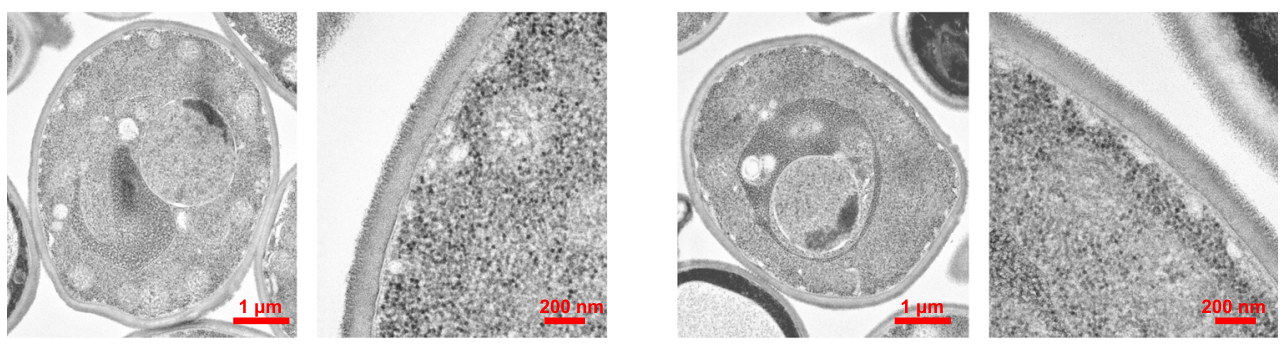

C
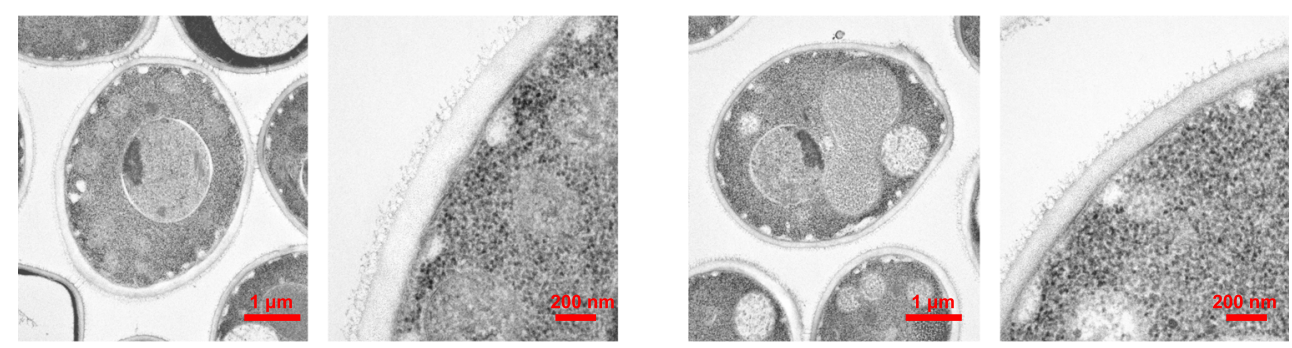

d
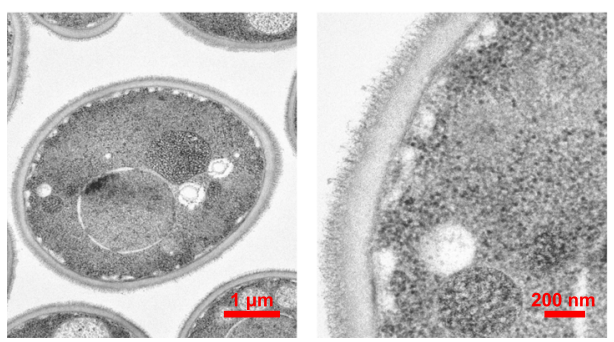
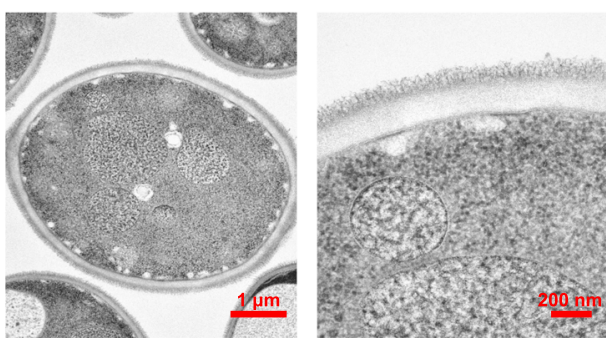

The molecular mechanism underlying morphological changes in the cell wall and increased heterologous protein capacity in the $C C W 12$ and $C C W 14$ co-knockout strains is still unclear. It has been reported that yeast cells lacking CCW12 show increased chitin content and hypersensitivity to chitin-binding reagents CFW and CR (Klis 1994). Also, deletion of $C C W 14$ leads to increased sensitivity to these reagents (Moukadiri et al. 1997). Chitin is one of the main components of the yeast cell wall. Chitin and glucan are covalently linked to form a network that is responsible for the mechanical strength of the cell wall (Arroyo et al. 2016). Severe chitin abnormality caused by the CCW 12 and CCW14 co-disruption might have reduced the mechanical strength of the chitin-glucan network and increased the flexibility of the cell wall of the ccw12/ccw14-BGSD strain, increasing the cell wall thickness. We performed sensitivity assays to $\mathrm{CFW}$ and $\mathrm{CR}$ for the BGL-displaying strains (Supplemental Fig. S2). The CCW12 and CCW14 coknockout strains (ccw12/ccw14-BGSD) showed increased sensitivity to CFW and CR compared with the control strain (BY-BG-SSSD) and ccw12-BGSD and ccw14-BGSD strains. This result also supports the severe chitin abnormality in ccw12/ccw14-BGSD. In contrast, ccw12-BGSD and ccw14BGSD strains were not sensitive to CFW and CR contrary to previous reports, which showed that the deletion of $C C W 12$ or CCW14 in S. cerevisiae markedly increases sensitivity to these reagents (Moukadiri et al. 1997; Mrsa et al. 1999). One possible cause for the insensitivity of ccw12-BGSD and ccw14-BGSD to CFW and CR in the present study might be the use of Sed1p as the GPI anchoring domain for the cell- 
surface display of BGL. Shankarnarayan et al. (2008) reported that the hypersensitivity of the $S$. cecevisiae ccw 12 mutant to CFW and CR is partially suppressed by elevated SED1 expression. Sed $1 p$ as the GPI anchoring domain might also have played a role in suppressing the CFW and CR sensitivities of these strains. Sensitivity assays to CFW and CR and the electron microscopic observation using the $C C W 12$ and $C C W 14$ co-knockout strains without BGL display may help to better understand the function of these GPI-CWPs.

To verify generality and applicability of the CCW12 and $C C W 14$ co-disruption strategy, we constructed the BGLdisplaying strains using $\mathrm{C}$-terminal domain of $\alpha$-agglutinin (Sag1p), which is one of the major GPI anchoring domains used in the surface display of heterologous proteins (van der Vaart et al. 1997), instead of Sed1p (BY-BG-SSAD, Table 1) and investigated the effect of $C C W 12$ and $C C W 14$ knockout on its cell surface activity of BGL1 (Supplemental Fig. S3). The CCW12 and CCW14 co-disruption resulted in an approximate 1.2-fold increase in the cell-surface BGL activity of this strain, suggesting that this strategy could be applied to cellsurface display technology with not only Sed1p, also other GPI-CWPs. We also constructed the yeast strains displaying Trichoderma reesei EGII using Sed1p as the GPI anchoring domain (BY-EG-SSSD, Table 1) and investigated the effect of $C C W 12$ and $C C W 14$ knockout on its hydrolytic activity for water-insoluble cellulose (Supplemental Fig. S4). In contrast to the BGL activity, the hydrolytic activity of the EGdisplaying strains was not significantly increased by $C C W 12$ and $C C W 14$ co-disruption. The substrate of BGL1 ( $p$ NPG) is a small molecule that can penetrate the cell wall and access all cell wall-associated enzymes, whereas water-insoluble cellulose, the substrate of EGII, is a large molecule and can only access the enzymes exposed on the external surface of the cell wall (Inokuma et al. 2020). Since the surface area of the cell wall would remain largely unchanged by increasing its thickness, CCW12 and CCW14 co-disruption might not have contributed to the cellulolytic activity of EG. The generality and applicability of the $C C W 12$ and $C C W 14$ co-disruption strategy would need to be further investigated using other proteins as well.

The results demonstrated in this study indicated that combinatorial engineering of multiple genes involved in the cell wall organization could be a promising approach to improve yeast cell-surface display technology, while they also suggested the difficulty of predicting the phenotypes caused by combinatorial engineering. Further exploration of yeast strains suitable for the cell-surface display technology using this approach would require the construction of a yeast genomic library with combinatorial engineering of multiple cell wallrelated genes. Recently, several methods for the construction of a comprehensive yeast genomic library applying the CRISPR system have been proposed (Jakočiūnas et al. 2015; Lian et al. 2019). These technologies may be useful for combinatorial engineering to screen promising host strains for the yeast cell-surface display.

In conclusion, we investigated the effect of $C C W 12$ and $C C W 14$ disruption on the surface display efficiency of heterologous proteins using A. aculeatus BGL1 as the model protein. We found that the amount of cell wall-associated BGL and its activity in the $C C W 12$ and $C C W 14$ co-knockout strain were approximately 1.4-fold higher than those of the parental strain. Electron microscopic observation revealed that the total cell wall thickness of the $C C W 12$ and $C C W 14$ co-knockout strains was increased compared to the parental strain, suggesting an increase in the heterologous protein carrying capacity of the cell wall. Although further research is needed to elucidate the molecular mechanism, results of this study indicated that the $C C W 12$ and $C C W 14$ co-knockout strains are a promising host for the construction of highly functional recombinant yeast strains using cell-surface display technology. For example, the use of this strain for the production of whole cell catalysts could potentially speed up bioconversion and biodegradation processes and improve the sensitivity of biosensing. Furthermore, in the applications of antigen-displaying cells as vaccines (Lei et al. 2016; Lei et al. 2020), by increasing the amount of antigenic protein per cell weight, it would be able to induce an effective antigen-specific immune response with lower vaccine doses.

Supplementary Information The online version contains supplementary material available at https://doi.org/10.1007/s00253-021-11440-6.

Code availability Not applicable.

Author contribution $\mathrm{KI}$ designed the research and wrote the manuscript. TB designed the experiments. KI, TB, Y Kitada, and Y Kobayashi, TY performed the experiments. RDH, WHVZ, AK, and TH revised the manuscript. AK and TH conceived and supervised the research. All authors read and approved the manuscript.

Funding This work was supported in part by Japan Society for the Promotion of Science (JSPS) KAKENHI Grant Number JP18K05554, and JSPS and National Research Foundation (NRF) of South Africa under the JSPS-NRF Joint Research Program (JSPS Grant Number JPJSBP120196503 and NRF Grant Number 118894).

Data availability All relevant data generated during this study are included in the article and its supplementary information file.

\section{Declarations}

Ethics approval Not applicable.

Consent to participate Not applicable.

Consent for publication The authors approved the manuscript submission to Applied Microbiology and Biotechnology.

Conflict of interest The authors declare no competing interests. 


\section{References}

Angelini A, Chen TF, de Picciotto S, Yang NJ, Tzeng A, Santos MS, Van Deventer JA, Traxlmayr MW, Wittrup KD (2015) Protein engineering and selection using yeast surface display. Methods Mol Biol 1319:3-36. https://doi.org/10.1007/978-1-4939-2748-7_1

Arroyo J, Farkaš V, Sanz AB, Cabib E (2016) Strengthening the fungal cell wall through chitin-glucan cross-links: effects on morphogenesis and cell integrity. Cell Microbiol 18(9):1239-1250. https://doi. org/10.1111/cmi.12615

Bamba T, Inokuma K, Hasunuma T, Kondo A (2018) Enhanced cellsurface display of a heterologous protein using SED1 anchoring system in SED1-disrupted Saccharomyces cerevisiae strain. J Biosci Bioeng 125(3):306-310. https://doi.org/10.1016/j.jbiosc. 2017.09.013

Chen DC, Yang BC, Kuo TT (1992) One-step transformation of yeast in stationary phase. Curr Genet 21(1):83-84. https://doi.org/10.1007/ BF00318659

Grzeschik J, Hinz SC, Könning D, Pirzer T, Becker S, Zielonka S, Kolmar H (2017) A simplified procedure for antibody engineering by yeast surface display: coupling display levels and target binding by ribosomal skipping. Biotechnol J 12(2). https://doi.org/10.1002/ biot. 201600454

Inokuma K, Hasunuma T, Kondo A (2014) Efficient yeast cell-surface display of exo- and endo-cellulase using the SEDI anchoring region and its original promoter. Biotechnol Biofuels 7(1):8. https://doi. org/10.1186/1754-6834-7-8

Inokuma K, Yoshida T, Ishii J, Hasunuma T, Kondo A (2015) Efficient co-displaying and artificial ratio control of $\alpha$-amylase and glucoamylase on the yeast cell surface by using combinations of different anchoring domains. Appl Microbiol Biotechnol 99(4): 1655-1663. https://doi.org/10.1007/s00253-014-6250-1

Inokuma K, Bamba T, Ishii J, Ito Y, Hasunuma T, Kondo A (2016) Enhanced cell-surface display and secretory production of cellulolytic enzymes with Saccharomyces cerevisiae Sed1 signal peptide. Biotechnol Bioeng 113(11):2358-2366. https://doi.org/10.1002/bit. 26008

Inokuma K, Hasunuma T, Kondo A (2018) Whole cell biocatalysts using enzymes displayed on yeast cell surface. In: Chang $\mathrm{H}$ (ed) Emerging Areas in Bioengineering. Wiley-VCH, New York, pp 81-92

Inokuma K, Kurono H, den Haan R, van Zyl WH, Hasunuma T, Kondo A (2020) Novel strategy for anchorage position control of GPIattached proteins in the yeast cell wall using different GPIanchoring domains. Metab Eng 57:110-117. https://doi.org/10. 1016/j.ymben.2019.11.004

Ishii J, Izawa $\mathrm{K}$, Matsumura S, Wakamura $\mathrm{K}$, Tanino T, Tanaka T, Ogino C, Fukuda H, Kondo A (2009) A simple and immediate method for simultaneously evaluating expression level and plasmid maintenance in yeast. J Biochem 145(6):701-708. https://doi.org/10. 1093/jb/mvp028

Ito Y, Kitagawa T, Yamanishi M, Katahira S, Izawa S, Irie K, FurutaniSeiki M, Matsuyama T (2016) Enhancement of protein production via the strong DIT1 terminator and two RNA-binding proteins in Saccharomyces cerevisiae. Sci Rep 6:36997. https://doi.org/10. 1038/srep36997

Jakočiūnas T, Bonde I, Herrgård M, Harrison SJ, Kristensen M, Pedersen LE, Jensen MK, Keasling JD (2015) Multiplex metabolic pathway engineering using CRISPR/Cas9 in Saccharomyces cerevisiae. Metab Eng 28:213-222. https://doi.org/10.1016/j.ymben.2015.01. 008

Katahira S, Mizuike A, Fukuda H, Kondo A (2006) Ethanol fermentation from lignocellulosic hydrolysate by a recombinant xylose- and cellooligosaccharide-assimilating yeast strain. Appl Microbiol Biotechnol 72:1136-1143. https://doi.org/10.1007/s00253-0060402-x
Klis FM (1994) Review: cell wall assembly in yeast. Yeast 10(7):851869. https://doi.org/10.1002/yea.320100702

Lei H, Jin S, Karlsson E, Schultz-Cherry S, Ye K (2016) Yeast surfacedisplayed H5N1 avian Influenza vaccines. J Immunol Res 2016: 4131324-4131312. https://doi.org/10.1155/2016/4131324

Lei H, Xie B, Gao T, Cen Q, Ren Y (2020) Yeast display platform technology to prepare oral vaccine against lethal H7N9 virus challenge in mice. Microb Cell Factories 19(1):53. https://doi.org/10. 1186/s12934-020-01316-1

Lesage G, Bussey H (2006) Cell wall assembly in Saccharomyces cerevisiae. Microbiol Mol Biol Rev : MMBR 70(2):317-343. https://doi.org/10.1128/MMBR.00038-05

Li B, Scarselli M, Knudsen CD, Kim SK, Jacobson KA, McMillin SM, Wess J (2007) Rapid identification of functionally critical amino acids in a G protein-coupled receptor. Nat Methods 4(2):169-174. https://doi.org/10.1038/nmeth990

Lian J, Schultz C, Cao M, HamediRad M, Zhao H (2019) Multifunctional genome-wide CRISPR system for high throughput genotype-phenotype mapping. Nat Commun 10(1):5794. https:// doi.org/10.1038/s41467-019-13621-4

Liu Z, Ho SH, Sasaki K, den Haan R, Inokuma K, Ogino C, van Zyl WH, Hasunuma T, Kondo A (2016) Engineering of a novel celluloseadherent cellulolytic Saccharomyces cerevisiae for cellulosic biofuel production. Sci Rep 6:24550. https://doi.org/10.1038/srep24550

Liu Z, Inokuma K, Ho SH, den Haan R, van Zyl WH, Hasunuma T, Kondo A (2017) Improvement of ethanol production from crystalline cellulose via optimizing cellulase ratios in cellulolytic Saccharomyces cerevisiae. Biotechnol Bioeng 114(6):1201-1207. https://doi.org/10.1002/bit.26252

Lu CF, Kurjan J, Lipke PN (1994) A pathway for cell-wall anchorage of Saccharomyces cerevisiae alpha-agglutinin. Mol Cell Biol 14(7): 4825-4833. https://doi.org/10.1128/mcb.14.7.4825

Moreno-García J, Coi AL, Zara G, García-Martínez T, Mauricio JC, Budroni M (2018) Study of the role of the covalently linked cell wall protein (Ccw14p) and yeast glycoprotein (Ygp1p) within biofilm formation in a flor yeast strain. FEMS Yeast Res 18(2). https:// doi.org/10.1093/femsyr/foy005

Moukadiri I, Armero J, Abad A, Sentandreu R, Zueco J (1997) Identification of a mannoprotein present in the inner layer of the cell wall of Saccharomyces cerevisiae. J Bacteriol 179(7):2154-2162. https://doi.org/10.1128/jb.179.7.2154-2162.1997

Mrsa V, Ecker M, Strahl-Bolsinger S, Nimtz M, Lehle L, Tanner W (1999) Deletion of new covalently linked cell wall glycoproteins alters the electrophoretic mobility of phosphorylated wall components of Saccharomyces cerevisiae. J Bacteriol 181(10):3076-3086. https://doi.org/10.1128/JB.181.10.3076-3086.1999

Nambu-Nishida Y, Nishida K, Hasunuma T, Kondo A (2017) Development of a comprehensive set of tools for genome engineering in a cold- and thermo-tolerant Kluyveromyces marxianus yeast strain. Sci Rep 7(1):8993. https://doi.org/10.1038/s41598-01708356-5

Ragni E, Sipiczki M, Strahl S (2007) Characterization of Ccw12p, a major key player in cell wall stability of Saccharomyces cerevisiae. Yeast 24(4):309-319. https://doi.org/10.1002/yea.1465

Ragni E, Piberger H, Neupert C, García-Cantalejo J, Popolo L, Arroyo J, Aebi M, Strahl S (2011) The genetic interaction network of CCW12, a Saccharomyces cerevisiae gene required for cell wall integrity during budding and formation of mating projections. BMC Genomics 12:107. https://doi.org/10.1186/1471-2164-12-107

Shankarnarayan S, Malone CL, Deschenes RJ, Fassler JS (2008) Modulation of yeast $\operatorname{Sin} 1$ kinase activity by the CCW12 cell wall protein. J Biol Chem 283(4):1962-1973. https://doi.org/10.1074/ jbc.M706877200

Shibasaki S, Ueda M, Ye K, Shimizu K, Kamasawa N, Osumi M, Tanaka A (2001) Creation of cell surface-engineered yeast that display different fluorescent proteins in response to the glucose concentration. 
Appl Microbiol Biotechnol 57(4):528-533. https://doi.org/10.1007/ s002530100767

Shibasaki S, Kawabata A, Tanino T, Kondo A, Ueda M, Tanaka M (2009) Evaluation of the biodegradability of polyurethane and its derivatives by using lipase-displaying arming yeast. Biocontrol Sci 14(4):171-175. https://doi.org/10.4265/bio.14.171

Shusta EV, Kieke MC, Parke E, Kranz DM, Wittrup KD (1999) Yeast polypeptide fusion surface display levels predict thermal stability and soluble secretion efficiency. J Mol Biol 292(5):949-956. https://doi.org/10.1006/jmbi.1999.3130

van der Vaart JM, te Biesebeke R, Chapman JW, Toschka HY, Klis FM, Verrips CT (1997) Comparison of cell wall proteins of Saccharomyces cerevisiae as anchors for cell surface expression of heterologous proteins. Appl Environ Microbiol 63(2):615-620. https://doi.org/10.1128/aem.63.2.615-620.1997

Wang H, Lang Q, Li L, Liang B, Tang X, Kong L, Mascini M, Liu A (2013) Yeast surface displaying glucose oxidase as whole-cell biocatalyst: construction, characterization, and its electrochemical glucose sensing application. Anal Chem 85(12):6107-6112. https://doi. org/10.1021/ac400979r
Wentz AE, Shusta EV (2007) A novel high-throughput screen reveals yeast genes that increase secretion of heterologous proteins. Appl Environ Microbiol 73(4):1189-1198. https://doi.org/10.1128/AEM. 02427-06

Yamakawa S, Yamada R, Tanaka T, Ogino C, Kondo A (2012) Repeated fermentation from raw starch using Saccharomyces cerevisiae displaying both glucoamylase and $\alpha$-amylase. Enzym Microb Technol 50(6-7):343-347. https://doi.org/10.1016/j.enzmictec. 2012.03.005

Zhao SX, Guo YH, Wang QN, Luo HL, He CZ, An B (2020) Expression of flagellin at yeast surface increases biocontrol efficiency of yeast cells against postharvest disease of tomato caused by Botrytis cinerea. Postharvest Biol Technol 162:111112. https://doi.org/10. 1016/j.postharvbio.2019.111112

Publisher's note Springer Nature remains neutral with regard to jurisdictional claims in published maps and institutional affiliations. 


\section{Terms and Conditions}

Springer Nature journal content, brought to you courtesy of Springer Nature Customer Service Center GmbH ("Springer Nature").

Springer Nature supports a reasonable amount of sharing of research papers by authors, subscribers and authorised users ("Users"), for smallscale personal, non-commercial use provided that all copyright, trade and service marks and other proprietary notices are maintained. By accessing, sharing, receiving or otherwise using the Springer Nature journal content you agree to these terms of use ("Terms"). For these purposes, Springer Nature considers academic use (by researchers and students) to be non-commercial.

These Terms are supplementary and will apply in addition to any applicable website terms and conditions, a relevant site licence or a personal subscription. These Terms will prevail over any conflict or ambiguity with regards to the relevant terms, a site licence or a personal subscription (to the extent of the conflict or ambiguity only). For Creative Commons-licensed articles, the terms of the Creative Commons license used will apply.

We collect and use personal data to provide access to the Springer Nature journal content. We may also use these personal data internally within ResearchGate and Springer Nature and as agreed share it, in an anonymised way, for purposes of tracking, analysis and reporting. We will not otherwise disclose your personal data outside the ResearchGate or the Springer Nature group of companies unless we have your permission as detailed in the Privacy Policy.

While Users may use the Springer Nature journal content for small scale, personal non-commercial use, it is important to note that Users may not:

1. use such content for the purpose of providing other users with access on a regular or large scale basis or as a means to circumvent access control;

2. use such content where to do so would be considered a criminal or statutory offence in any jurisdiction, or gives rise to civil liability, or is otherwise unlawful;

3. falsely or misleadingly imply or suggest endorsement, approval, sponsorship, or association unless explicitly agreed to by Springer Nature in writing;

4. use bots or other automated methods to access the content or redirect messages

5. override any security feature or exclusionary protocol; or

6. share the content in order to create substitute for Springer Nature products or services or a systematic database of Springer Nature journal content.

In line with the restriction against commercial use, Springer Nature does not permit the creation of a product or service that creates revenue, royalties, rent or income from our content or its inclusion as part of a paid for service or for other commercial gain. Springer Nature journal content cannot be used for inter-library loans and librarians may not upload Springer Nature journal content on a large scale into their, or any other, institutional repository.

These terms of use are reviewed regularly and may be amended at any time. Springer Nature is not obligated to publish any information or content on this website and may remove it or features or functionality at our sole discretion, at any time with or without notice. Springer Nature may revoke this licence to you at any time and remove access to any copies of the Springer Nature journal content which have been saved.

To the fullest extent permitted by law, Springer Nature makes no warranties, representations or guarantees to Users, either express or implied with respect to the Springer nature journal content and all parties disclaim and waive any implied warranties or warranties imposed by law, including merchantability or fitness for any particular purpose.

Please note that these rights do not automatically extend to content, data or other material published by Springer Nature that may be licensed from third parties.

If you would like to use or distribute our Springer Nature journal content to a wider audience or on a regular basis or in any other manner not expressly permitted by these Terms, please contact Springer Nature at

onlineservice@springernature.com 